\title{
Factors associated with survival in patients with COVID - I9 admitted to a community hospital in New York City
}

\begin{abstract}
Introduction: COVID-19 has been associated with increased mortality in old age, hypertension and male gender. Higher prevalence of increased body mass index (BMI), mechanical ventilation and renal failure has been found in the patients admitted to our New York City community hospital; accordingly we aim to explore the association between these parameters and survival in our patients.
\end{abstract}

Methods: Retrospective review of patients admitted with the COVID-19 disease March 14 to April 30 of 2020. Analysis using Cox regression models, Log rank tests and Kaplan Meier curves was done for a total of 326 patients that met our criteria.

Results: The adjusted odds of death for those at least 75 years of age were higher than those within the age group of 18 to 44 years. The patients with over $92 \%$ oxygen saturation had lower adjusted odds of death than those with 88 to $92 \%$ oxygen saturation (Odds Ratio $(\mathrm{OR})=0.2,95 \% \mathrm{CI}=0.06,0.70)$, as well as lower adjusted hazard of dying (Hazard Ratio $(\mathrm{HR})=0.4,95 \% \mathrm{CI}=0.21,0.87)$. Intubation was associated with a higher adjusted odds ratio $(\mathrm{OR}=57.8,95 \% \mathrm{CI}=17.74,188.30)$ and adjusted hazard ratio $\mathrm{HR}=5.4(95 \% \mathrm{CI}=2.59$, 11.21) for death. After controlling for age and gender, neither levels of serum D-dimer nor creatinine were found to be significantly associated with mortality

The factors that comprise metabolic syndrome, i.e., elevated BMI, diabetes, hypertension, and hyperlipidemia, were found to have no significant association with the outcome of death after controlling for age and sex and they also had no significant association with the time until death.

Conclusions: In the study population, COVID-19 was associated with increased mortality in patients who required intubation, and in the elderly, which may be explained by changes in the immune system over time.

Elevated BMI, though not statistically significant, was present in the majority of our study population, which may have contributed to the group's high mortality.

Keywords: COVID-19, Corona virus, Pandemic, Outcomes, New York, NYC
Volume 8 Issue 2 - 2021

\author{
Ajay P Singh, ${ }^{1,2}$ Ahmed Shady, ${ }^{1,2}$ Ejiro Gbaje, ${ }^{1,2}$ \\ Marlon Oliva, ${ }^{1,2}$ Samantha Golden- \\ Espinal, ${ }^{2}$ Dylan Macciola, ${ }^{2}$ Dyanna Soto, ${ }^{2}$ \\ William E. Eddy, ${ }^{2}$ Anusha Adkoli, ${ }^{2}$ Noella \\ Boma, ${ }^{1,2,3}$ Nora V. Bergasa ${ }^{1,2,3}$ \\ 'Department of Medicine, NYC Health+Hospitals/Metropolitan, \\ USA \\ ${ }^{2}$ Department of Medicine, New York Medical College, USA \\ ${ }^{3}$ Department of Medicine, Physician Affiliate Group of New \\ York, USA
}

Correspondence: Ahmed Shady, Department of Medicine, NYC Health, Hospitals / Metropolitan, New York, USA, Email Ahmed.shady@nychhc.org

Received: January 15, 202I | Published: April 01, 202 |
Abbreviations: COVID-19, corona virus disease 2019; BMI, body mass index; OR, odds ratio; VIF, variance inflation factors; HR, hazard ratio

\section{Introduction}

After the emergence of the disease in China in the latter part of 2019, severe acute respiratory syndrome virus -2 (SARS CoV-2) spread across the world. Twelve million people have been affected by this virus, with 0.56 million deaths globally. ${ }^{1}$

Although old age, hypertension, and male gender have been reported in association with increased mortality in patients with COVID-19, ${ }^{2,3}$ body mass index (BMI), mechanical ventilation, and renal failure were highly prevalent in the patients admitted to our hospital with the disease ${ }^{4}$. Accordingly, we aimed to explore the association between BMI, mechanical ventilation, and renal failure with the survival of patients admitted with COVID-19 to a community hospital in New York City during the early period of the pandemic.

\section{Methods}

The data source for this study was the database designed for characterization of patients admitted to the hospital with COVID-19, and approved by the institutional review board. The study group was comprised of 326 patients who had been hospitalized from March $14^{\text {th }}$ to April $30^{\text {th }}$ of 2020 and discharged from the hospital or had died.

Univariate statistics were calculated for the non-missing observations of all the variables. All the continuous variables were categorized using the defined normal limits, and the frequencies and the percentages were computed.

Logistic regression models for metabolic syndrome, respiratory factors, and D-dimer were used to compute the unadjusted and adjusted associations between predictors and the outcome of death. Odds ratio (OR) were calculated. Fifth's logistic regression technique was applied to reduce sample bias and address low cell counts. Predictors were selected using a priori selection. Variance inflation factors (VIF) were calculated to assess multicollinearity (if VIF $\geq 2$ ). 
Log rank tests were used to assess the survival estimate equality for predictors, and Kaplan Meier curves were produced for the predictors that had significant differences in survival estimates. Cox regression models for the metabolic syndrome and respiratory factors, and plasma D-dimer levels were used to predict the hazard ratios (HR) for time until death. Efron's method was applied to account for the high number of ties in the study sample. All models were controlled for age and sex. The proportional hazards assumption was tested for all Cox regression models.

\section{Results}

The majority of patients, $67.5 \%$, was men, had a high BMI, $76.3 \%$, and the minority, $12 \%$, and was older than 75 years (Table 1 ). Comorbidities included hypertension in $47 \%$ of the group, diabetes in $41 \%$, and hyperlipidemia in $28 \%$. The vital signs on admission were notable for tachypnea in $32 \%$ of the patients, with $12 \%$ being hypoxemic at the time of arrival, and $22 \%$ requiring intubation during the hospitalization. However, the majority, $66 \%$, was admitted with oxygen saturation greater than $92 \%$ (Table 1). Fifty-seven percent of the patients had an abnormal serum creatinine, and $76 \%$ had a high plasma D-dimer level on admission.

Table I Characteristics of COVID-positive patients at metropolitan hospital who died in hospital or were discharged alive $(n=326)$

\begin{tabular}{|c|c|c|}
\hline \multicolumn{3}{|l|}{ Demographics } \\
\hline & $\mathbf{N}$ & $\%$ \\
\hline Total & 326 & \\
\hline \multicolumn{3}{|l|}{ Age in years } \\
\hline 18-44 & 96 & 29.45 \\
\hline $45-54$ & 59 & 18.1 \\
\hline $55-64$ & 77 & 23.62 \\
\hline $65-74$ & 55 & 16.87 \\
\hline$\geq 75$ & 39 & 11.96 \\
\hline \multicolumn{3}{|l|}{ Gender } \\
\hline Male & 220 & 67.48 \\
\hline Female & 106 & 32.52 \\
\hline Hypertension & 154 & 47.24 \\
\hline Hyperlipidemia & 91 & 28 \\
\hline Diabetes Mellitus & 134 & 41.1 \\
\hline \multicolumn{3}{|l|}{ Body Mass Index } \\
\hline Underweight $(<18.5)$ & 5 & 1.71 \\
\hline Normal $(18.5-<25)$ & 64 & 21.92 \\
\hline Elevated $(\geq 25)$ & 223 & 76.37 \\
\hline \multicolumn{3}{|l|}{ Respiratory Rate } \\
\hline$\leq 20$ rpm (Normal) & 217 & 68.03 \\
\hline >20rpm (Abnormal) & 102 & 31.97 \\
\hline
\end{tabular}

Table Continues.

\begin{tabular}{|c|c|c|}
\hline \multicolumn{3}{|l|}{ Demographics } \\
\hline & $\mathbf{N}$ & $\%$ \\
\hline \multicolumn{3}{|c|}{$\begin{array}{l}\text { Percent Oxygen Saturation } \\
\text { on Presentation }\end{array}$} \\
\hline$<88 \%$ & 39 & 11.96 \\
\hline $88-92 \%$ & 72 & 22.09 \\
\hline$>92 \%$ & 215 & 65.95 \\
\hline \multicolumn{3}{|l|}{$\mathrm{PCO}_{2}$} \\
\hline Low (<35 mmHg) & 52 & 21.31 \\
\hline Normal (35-48 mmHg) & 156 & 63.93 \\
\hline High (>48 mmHg) & 36 & 14.75 \\
\hline \multicolumn{3}{|l|}{$\mathrm{pH}$} \\
\hline Low $(<7.3)$ & 28 & 11.48 \\
\hline Normal (7.3-7.4) & 116 & 47.54 \\
\hline High (>7.4) & 100 & 40.98 \\
\hline Intubation & 71 & 21.78 \\
\hline \multicolumn{3}{|l|}{ D-dimer level } \\
\hline Normal (<230 ng/dL) & 57 & 23.55 \\
\hline Abnormal ( $\geq 230 \mathrm{ng} / \mathrm{dL})$ & 185 & 76.45 \\
\hline \multicolumn{3}{|l|}{ Serum Creatinine level } \\
\hline Normal (<0.9 mg/dL) & 140 & 43.08 \\
\hline Abnormal $(\geq 0.9 \mathrm{mg} / \mathrm{dL})$ & 185 & 56.92 \\
\hline
\end{tabular}

Note: Some frequencies do not add up to the total 326 due to missing observations.

Diabetes, hypertension, and hyperlipidemia were associated with an increase in the odds of death and hazard ratio in the unadjusted multivariable logistic regression model (Table 2) and the unadjusted Cox regression model (Table 3), respectively. The factors that comprise the metabolic syndrome, i.e., elevated BMI, diabetes, hypertension, and hyperlipidemia, were found to have no significant association with the outcome of death after controlling for age and sex and also had no significant association with the time until death.

The adjusted odds of death for those at least 75 years of age were higher than those within the age group of 18 to 44 years, 15.6 (95\% confidence interval $(\mathrm{CI})=4.60,53.08)$. The adjusted odds of death for those within the age group of 65 to 74 years were higher than those with age within 18 to 44 years, $6.3(95 \% \mathrm{CI}=2.16,18.39)$ as well. The hazard ratio of death for the patients aged 75 or older was $6.8(95 \%$ $\mathrm{CI}=2.27,20.47)$ times the hazard of death for the patients between the ages of 18 to 44 years, and those aged between 65 to 74 years 
had $3.6(95 \% \mathrm{CI}=1.28,10.06)$ times the hazard of death as compared to those within the age group of 18 to 44years. The proportional hazards assumption was met by the data in the model (Global Test Chi-Square $=13.06, p=0.220$ ), signifying that the trends in each hazard group were proportional and that the Cox proportional hazard was an appropriate test to be used.

Table 2 Logistic regression: metabolic syndrome (Firth's Logistic Regression)

\begin{tabular}{|c|c|c|c|c|}
\hline & $\begin{array}{l}\text { Unadjusted } \\
\text { OR ( } 95 \% \mathrm{Cl})\end{array}$ & $\mathrm{p}$-value & $\begin{array}{l}\text { Adjusted } \\
\text { OR }(95 \% \mathrm{Cl})\end{array}$ & p-value \\
\hline \multicolumn{5}{|l|}{ Age, in years } \\
\hline 18 to 44 & I (ref) & & I (ref) & \\
\hline 45 to 54 & $1.45(0.48,4.37)$ & 0.509 & $(1.47(0.46,4.72)$ & 0.513 \\
\hline 55 to 64 & $2.96(1.14,7.50)$ & $0.022^{*}$ & $2.49(0.85,7.28)$ & 0.095 \\
\hline 65 to 74 & $8.63(3.46,21.54)$ & $<0.001 *$ & $6.30(2.16,18.39)$ & $0.001 *$ \\
\hline$>75$ & $18.86(7.08,50.24)$ & $<0.001 *$ & $15.62(4.60,53.08)$ & $<0.001 *$ \\
\hline \multicolumn{5}{|l|}{ Sex } \\
\hline Male & $1.20(0.69,2.09)$ & 0.523 & $1.30(0.67,2.53)$ & 0.433 \\
\hline Female & I (ref) & & I (ref) & \\
\hline \multicolumn{5}{|l|}{ BMI } \\
\hline Underweight BMI & $0.90(0.13,6.22)$ & 0.919 & $0.39(0.05,3.36)$ & 0.395 \\
\hline Normal BMI & I (ref) & & I (ref) & \\
\hline Elevated BMI & $0.77(0.4 \mathrm{I}, \mathrm{I} .45)$ & 0.42 & I.II $(0.52,2.36)$ & 0.783 \\
\hline Diabetes Mellitus & $2.04(1.21,3.43)$ & $0.007^{*}$ & $1.00(0.52,1.93)$ & 0.993 \\
\hline Hypertension & $4.15(2.36,7.31)$ & $<0.001 *$ & $1.40(0.67,2.94)$ & 0.373 \\
\hline Hyperlipidemia & $2.47(1.44,4.25)$ & $<0.001 *$ & $1.38(0.68,2.79)$ & 0.372 \\
\hline
\end{tabular}

Table 3 Cox regression: metabolic syndrome

\begin{tabular}{|c|c|c|c|}
\hline & aHR & $95 \% \mathrm{Cl}$ & p-value \\
\hline \multicolumn{4}{|l|}{ Age, in years } \\
\hline 18 to 44 & I (ref) & & \\
\hline 45 to 54 & 2.18 & $(0.69,6.89)$ & 0.184 \\
\hline 55 to 64 & 2.76 & $(0.96,7.91)$ & 0.059 \\
\hline 65 to 74 & 3.59 & $(1.28,10.06)$ & $0.015^{*}$ \\
\hline$>75$ & 6.82 & $(2.27,20.47)$ & $0.001 *$ \\
\hline \multicolumn{4}{|l|}{ Sex } \\
\hline Male & 0.88 & $(0.5 \mathrm{I}, \mathrm{I} .5 \mathrm{I})$ & 0.631 \\
\hline Female & I (ref) & & \\
\hline \multicolumn{4}{|l|}{ BMI } \\
\hline Underweight BMI & 0.26 & $(0.03,2.02)$ & 0.197 \\
\hline Normal BMI & I (ref) & & \\
\hline Elevated BMI & 0.71 & $(0.38,1.34)$ & 0.295 \\
\hline Diabetes Mellitus & 0.77 & $(0.42,1.41)$ & 0.399 \\
\hline Hypertension & 1.64 & $(0.83,3.24)$ & 0.155 \\
\hline Hyperlipidemia & 1.07 & $(0.59,1.92)$ & 0.827 \\
\hline
\end{tabular}

The patients with over $92 \%$ oxygen saturation had $80 \%$ lower odds of death than those with 88 to $92 \%$ oxygen saturation, with an $\mathrm{OR}=0.2$, $95 \% \mathrm{CI}=0.06,0.70$, as well as $58 \%$ lower hazard of dying $((\mathrm{HR})=0.4$, $95 \% \mathrm{CI}=0.21,0.87))$ after adjusting for other covariables. Intubation was associated with a higher odds of death $(\mathrm{OR}=57.8,95 \% \mathrm{CI}=17.74$, 188.30), as well as a higher hazard of death $(\mathrm{HR}=5.4(95 \% \mathrm{CI}=2.59$, $11.21)$ as compared to the patients who did not require intubation after adjusting for other covariables (Tables 4 \& 5).

Table 4 Logistic regression: respiratory status (Firth's Logistic Regression)

\begin{tabular}{|c|c|c|c|c|}
\hline & Unadjusted & p-value & Adjusted & p-value \\
\hline & OR $(95 \% \mathrm{Cl})$ & & OR $(95 \% \mathrm{Cl})$ & \\
\hline \multicolumn{5}{|l|}{ Age } \\
\hline 18 to 44 & I (ref) & & I (ref) & \\
\hline 45 to 54 & $1.45(0.48,4.37)$ & 0.509 & $0.97(0.13,6.91)$ & 0.972 \\
\hline 55 to 64 & $2.96(1.14,7.50)$ & $0.022^{*}$ & $3.97(0.90,17.59)$ & 0.069 \\
\hline 65 to 74 & $8.63(3.46,21.54)$ & $<0.001 *$ & $7.17(1.43,35.85)$ & $0.017^{*}$ \\
\hline$>75$ & I8.86 $(7.08,50.24)$ & $<0.00 I^{*}$ & 93.27 (I5.67.555.09) & $<0.00 I^{*}$ \\
\hline \multicolumn{5}{|l|}{ Sex } \\
\hline Male & $1.20(0.69,2.09)$ & 0.523 & I.88 $(0.62,5.72)$ & 0.268 \\
\hline Female & I (ref) & & I (ref) & \\
\hline \multicolumn{5}{|l|}{$\begin{array}{l}\text { Respiratory } \\
\text { Rate }\end{array}$} \\
\hline$<20 \mathrm{rpm}$ & I (ref) & & I (ref) & \\
\hline$>20 \mathrm{rpm}$ & $2.18(1.27,3.73)$ & $0.005^{*}$ & $1.29(0.46,3.60)$ & 0.628 \\
\hline $\begin{array}{l}\text { Percent Oxyge } \\
\text { Saturation on } \\
\text { Presentation }\end{array}$ & & & & \\
\hline$<88 \%$ & $5.28(2.27,12.28)$ & $<0.00 I^{*}$ & $1.76(0.37,8.23)$ & 0.475 \\
\hline $88-92 \%$ & I (ref) & & I (ref) & \\
\hline$>92 \%$ & $0.27(0.15,0.47)$ & $<0.00 I^{*}$ & $0.20(0.06,0.70)$ & $0.012 *$ \\
\hline \multicolumn{5}{|l|}{$\mathrm{pCO} 2$} \\
\hline $\begin{array}{l}\text { Low } \\
(<35 \mathrm{mmHg})\end{array}$ & $1.79(0.92,3.49)$ & 0.086 & $0.89(0.25,3.11)$ & 0.852 \\
\hline $\begin{array}{l}\text { Normal (35- } \\
48 \mathrm{mmHg})\end{array}$ & I (ref) & & I (ref) & \\
\hline $\begin{array}{l}\text { High } \\
(>48 \mathrm{mmHg})\end{array}$ & $1.57(0.73,3.40)$ & 0.252 & $0.83(0.21,3.30)$ & 0.793 \\
\hline \multicolumn{5}{|l|}{$\mathrm{pH}$} \\
\hline$<7.3$ & $3.64(1.57,8.46)$ & $0.003^{*}$ & $2.71(0.63,11.72)$ & 0.182 \\
\hline 7.3-7.4 & I (ref) & & I (ref) & \\
\hline$>7.4$ & $0.54(0.28,1.02)$ & 0.057 & $0.59(0.18,1.91)$ & 0.383 \\
\hline Intubation & $\begin{array}{l}38.64 \text { (18.98, } \\
78.69)\end{array}$ & $<0.00 I^{*}$ & $57.80(17.74,188.30)$ & $<0.00$ I $^{*}$ \\
\hline
\end{tabular}


Table 5 Cox regression: respiratory status

\begin{tabular}{|c|c|c|c|}
\hline & aHR & $95 \% \mathrm{Cl}$ & $\mathrm{p}$-value \\
\hline \multicolumn{4}{|l|}{ Age } \\
\hline 18 to 44 & I (ref) & & \\
\hline 45 to 54 & 2.18 & $(0.69,6.87)$ & 0.183 \\
\hline 55 to 64 & 2.26 & $(0.87,5.91)$ & 0.094 \\
\hline 65 to 74 & 2.06 & $(0.83,5.15)$ & 0.12 \\
\hline$>75$ & 11.46 & $(4.37,30.06)$ & $<0.001 *$ \\
\hline \multicolumn{4}{|l|}{ Sex } \\
\hline Male & 1.86 & $(1.01,3.44)$ & $0.048 *$ \\
\hline Female & I (ref) & & \\
\hline \multicolumn{4}{|l|}{ Respiratory Rate } \\
\hline$<20 \mathrm{rpm}$ & I (ref) & & \\
\hline$>20$ rpm & 0.96 & $(0.55,1.69)$ & 0.899 \\
\hline \multicolumn{4}{|c|}{$\begin{array}{l}\text { Percent Oxygen Saturation on } \\
\text { Presentation }\end{array}$} \\
\hline$<88 \%$ & 1.09 & $(0.48,2.50)$ & 0.831 \\
\hline $88-92 \%$ & I (ref) & & \\
\hline$>92 \%$ & 0.42 & $(0.21,0.87)$ & $0.019 *$ \\
\hline \multicolumn{4}{|l|}{$\mathrm{pCO} 2$} \\
\hline Low (<35 mmHg) & 0.81 & $(0.39,1.68)$ & 0.573 \\
\hline Normal $(35-48 \mathrm{mmHg})$ & I (ref) & & \\
\hline High (>48 mmHg) & 0.91 & $(0.40,2.07)$ & 0.818 \\
\hline \multicolumn{4}{|l|}{$\mathrm{pH}$} \\
\hline$<7.3$ & 3.27 & $(1.45,7.38)$ & $0.004 *$ \\
\hline 7.3-7.4 & I (ref) & & \\
\hline$>7.4$ & 0.6 & $(0.30,1.24)$ & 0.169 \\
\hline Intubation & 5.39 & $(2.59,11.21)$ & $<0.001 *$ \\
\hline
\end{tabular}

After controlling for age and gender, neither plasma levels of D-dimer nor serum creatinine were found to be significantly associated with mortality (Tables $6 \& 7$ ).

Table 6 Logistic regression: D-dimer and serum creatinine (Firth's Logistic Regression)

\begin{tabular}{|c|c|c|c|c|}
\hline & Unadjusted & p-value & Adjusted & p-value \\
\hline & OR $(95 \% \mathrm{Cl})$ & & OR $(95 \% \mathrm{Cl})$ & \\
\hline \multicolumn{5}{|l|}{ Age } \\
\hline 18 to 44 & I (ref) & & I (ref) & \\
\hline 45 to 54 & I. $45(0.48,4.37)$ & 0.509 & $1.14(0.32,4.13)$ & 0.838 \\
\hline 55 to 64 & $2.96(1.14,7.50)$ & $0.022^{*}$ & $2.13(0.74,6.14)$ & 0.162 \\
\hline 65 to 74 & $8.63(3.46,21.54)$ & $<0.00 I^{*}$ & $4.53(1.56,13.15)$ & $0.006 *$ \\
\hline$>75$ & $18.86(7.08,50.24)$ & $<0.00 I^{*}$ & $8.47(2.78,25.85)$ & $<0.001 *$ \\
\hline \multicolumn{5}{|l|}{ Sex } \\
\hline Male & $1.20(0.69,2.09)$ & 0.523 & $1.49(0.72,3.09)$ & 0.284 \\
\hline Female & I (ref) & & & \\
\hline
\end{tabular}

Table Continues.

\begin{tabular}{|c|c|c|c|c|}
\hline & Unadjusted & p-value & Adjusted & p-value \\
\hline & OR $(95 \% \mathrm{CI})$ & & OR $(95 \% \mathrm{Cl})$ & \\
\hline \multicolumn{5}{|l|}{ D-dimer level } \\
\hline $\begin{array}{l}\text { Normal } \\
(<230 \mathrm{ng} / \mathrm{dL})\end{array}$ & I (ref) & & I (ref) & \\
\hline $\begin{array}{l}\text { Abnormal } \\
(>230 \mathrm{ng} / \mathrm{dL})\end{array}$ & $4.80(1.74,13.22)$ & $<0.001 *$ & $2.77(0.95,8.06)$ & 0.062 \\
\hline \multicolumn{5}{|l|}{$\begin{array}{l}\text { Serum } \\
\text { Creatinine } \\
\text { level }\end{array}$} \\
\hline $\begin{array}{l}\text { Normal }(<0.9 \\
\mathrm{mg} / \mathrm{dL})\end{array}$ & I (ref) & & I (ref) & \\
\hline $\begin{array}{l}\text { Abnormal } \\
(>0.9 \mathrm{mg} / \mathrm{dL})\end{array}$ & $4.31(2.31,8.04)$ & $<0.00 I^{*}$ & $1.55(0.71,3.39)$ & 0.27 \\
\hline
\end{tabular}

Table 7 Cox regression: anticoagulation and D-dimer

\begin{tabular}{llll}
\hline & aHR & $95 \% \mathrm{Cl}$ & P-value \\
\hline Age & & & \\
\hline 18 to 44 & I (ref) & & \\
45 to 54 & 1.25 & $(0.35,4.46)$ & 0.735 \\
55 to 64 & 1.84 & $(0.66,5.14)$ & 0.242 \\
65 to 74 & 2.13 & $(0.76,5.96)$ & 0.15 \\
$>75$ & 4.2 & $(1.54,11.46)$ & $0.005^{*}$ \\
Sex & & & \\
\hline Male & I.29 & $(0.70,2.37)$ & 0.418 \\
Female & I (ref) & & \\
D-dimer level & & & \\
Normal $(<230 \mathrm{ng} / \mathrm{dL})$ & $\mathrm{I}(\mathrm{ref})$ & & \\
Abnormal $(>230 \mathrm{ng} / \mathrm{dL})$ & 2.21 & $(0.67,7.29)$ & 0.195 \\
Serum creatinine level & & & \\
\hline Normal $(<0.9 \mathrm{mg} / \mathrm{dL})$ & $\mathrm{I}(\mathrm{ref})$ & & \\
Abnormal $(>0.9 \mathrm{mg} / \mathrm{dL})$ & $\mathrm{I} .4$ & $(0.68,2.87)$ & \\
\hline
\end{tabular}

The overall median survival for the patients in our study was 17 days. Kaplan-Meier curves for the survival estimates for the overall survival, age, BMI, diabetes, percentage of oxygen saturation on arrival, and intubation are shown in Figures 1-6, respectively.

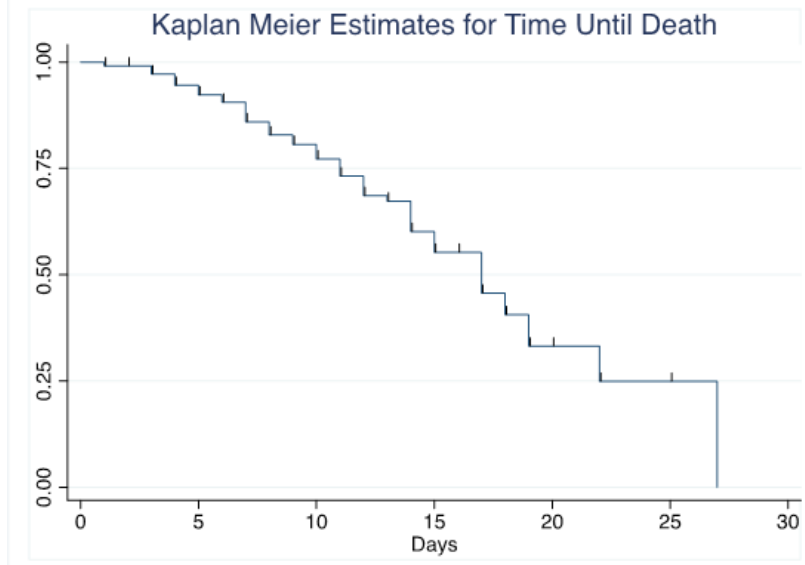

Figure I Kaplan Meier estimates for time until death. 


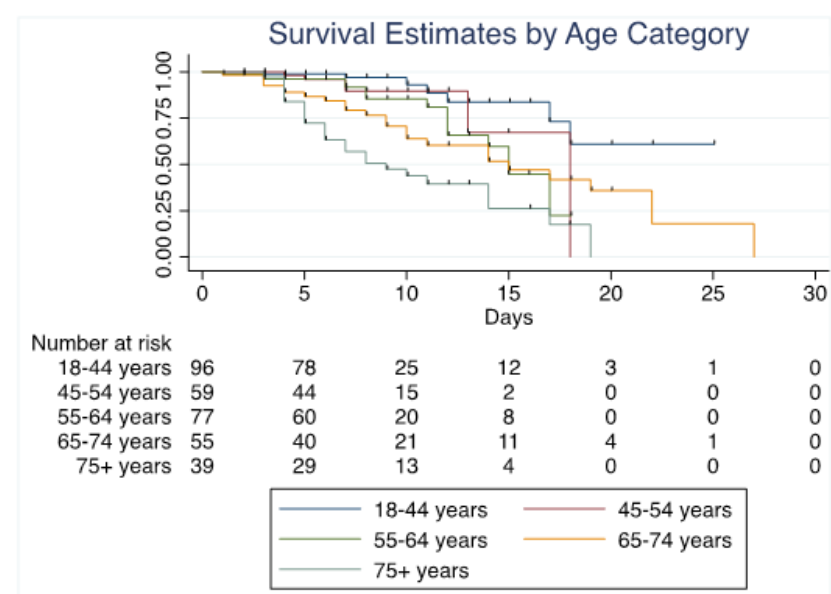

Figure 2 Survival estimates by BMI category.

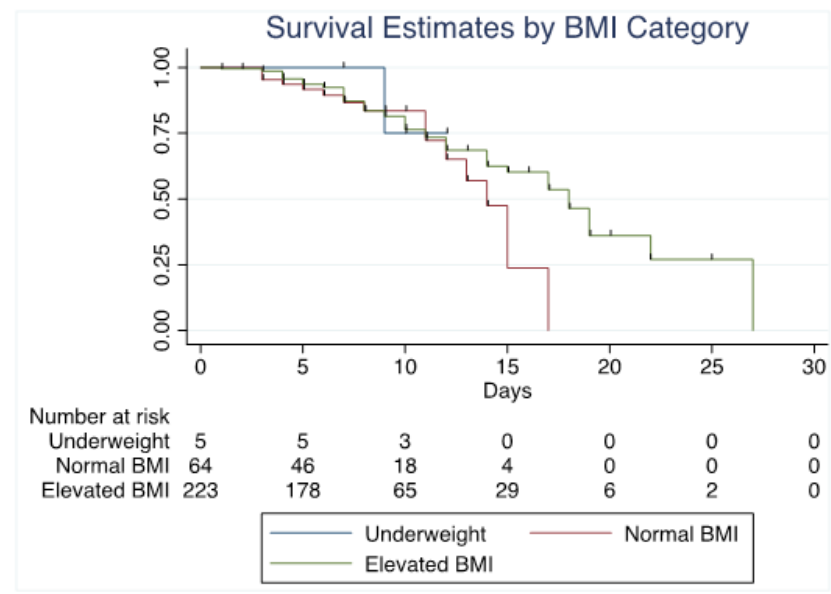

Figure 3 Survival estimates by intubation status.

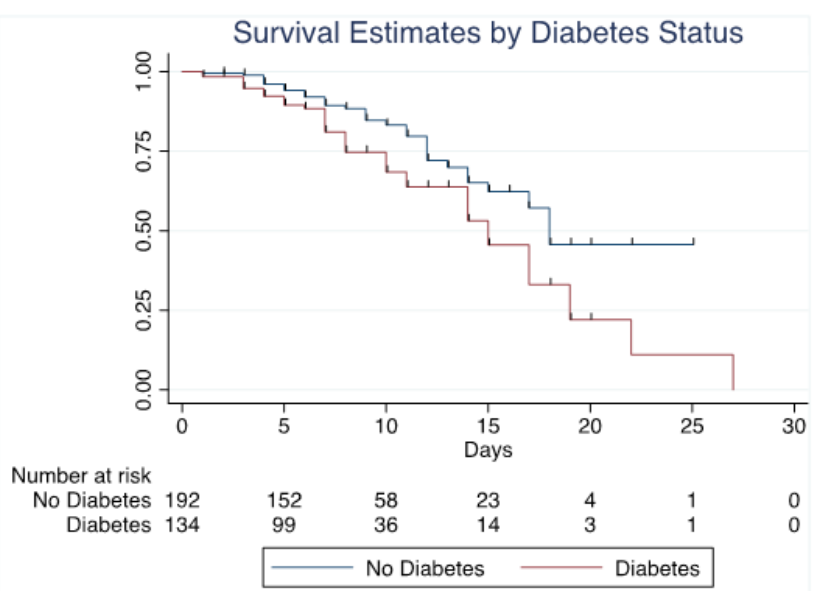

Figure 4 Survival estimates by age category.

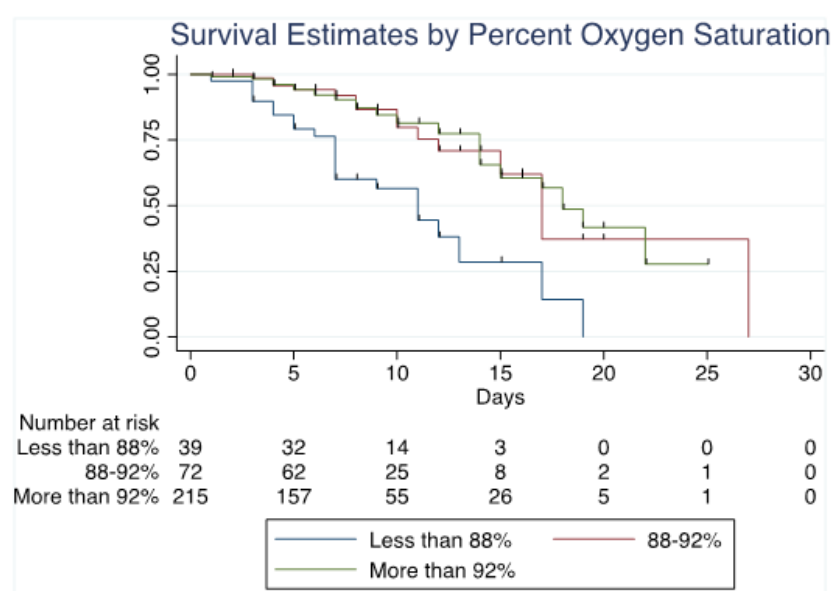

Figure 5 Survival estimates by diabetes status.

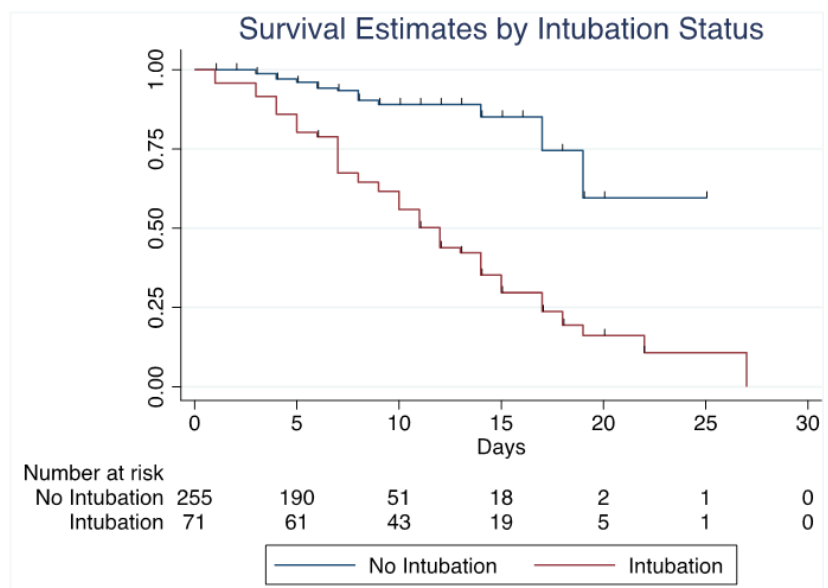

Figure 6 Survival estimates by percent oxygen saturation.

\section{Discussion}

In this study, age older than 75 years was associated with higher mortality than in the other age groups. An oxygen saturation of at least $92 \%$ at presentation, although consistent with hypoxemia, was associated with increased odds of survival, in contrast to intubation, which was associated with a significantly decreased odds of survival. We did not find any significant association between the plasma concentration of D -dimer or serum creatinine with mortality when adjusted for age and gender.

COVID-19 is associated with adverse outcomes in the elderly population, as documented in other conditions like bacterial or viral pneumonia; this may be related to the presence of comorbidities or a decrease in the competency of the immune system..$^{5,6}$ Decreased clearance of oral secretions, mucociliary function, and elastic recoil of the lungs are factors that put the elderly at an increased risk for complications from pneumonia. ${ }^{6}$ However, the waning immunity with aging has been challenged by the senescent remodeling theory of the immune system, ${ }^{7}$ which proposes the preservation or enhancement of innate immunity with increasing age and the existence of specific immune phenotypes that may put a person at an increased risk for 
infection, which results from complex changes in both the adaptive and innate immunity as a person ages. Nevertheless, aging has been statistically related to worse outcomes in patients with viral and bacterial pneumonia, evidenced by the inclusion of age as a common variable in different models predicting the severity of the disease, e.g., CURB-65, PSI, A-DROP. ${ }^{8-10}$ Elderly patients may also exhibit atypical symptoms of various infectious diseases including, pneumonia, urinary tract infections, and meningitis. Similarly, elderly patients with COVID-19 may present with diarrhea and delirium more frequently than patients in other age groups; hence, there may be a delay in seeking treatment, making a diagnosis, and providing subsequent specific management of the patients. ${ }^{10,11}$

Insulin resistance or the presence of conditions that comprise the metabolic syndrome have been considered to be associated with increased morbidity and mortality in patients with COVID-19. ${ }^{12-14}$ However, there was no statistically significant increased risk of death associated with the presence of metabolic syndrome after it was adjusted for age and gender in our study. One explanation for this finding is that the majority of the patients, more than three-fourths, in our study group, had an elevated BMI; hence, the patients with normal BMI were underrepresented, making the comparison insignificant. In this context, a limitation of our study is the predominance of patients with high BMI, which has limited our ability to assess the effect of COVID-19 in patients with normal BMI.

Intubation was needed for $25 \%$ of the patients, which is higher than the $2-17 \%$ reported in other publications. ${ }^{15-17}$ Intubation itself, in our study, was associated with a five time increase risk of dying as compared to the patients who did not require intubation. The increased need for intubation in our study may have been due to the high prevalence of obesity in the study population, as a high BMI is associated with poor respiratory function. ${ }^{18-20}$ ARDS, a complication of COVID- $19,{ }^{21,22}$ was present in $30 \%$ of the patients. One of the mechanisms proposed in the development of this complication is diffuse alveolar damage associated with the development of microthrombosis and endothelial cell damage. Furthermore, increased angiogenesis, specifically intussusceptive angiogenesis ${ }^{23}$, where a new vessel is formed by developing a pillar within the lumen of the vessel compared to sprouting angiogenesis wherein new channels bud from the existing vessels, has been observed more frequently in the patients with COVID-19. ${ }^{21}$ In addition, a recent study has suggested that pulmonary vascular dilatation contributes to development of hypoxemia in patients with COVID-19 pneumonia. $^{24}$

Increased odds of mortality and critical illness with an elevated serum creatinine level in patients with COVID-19 have been reported in other studies. ${ }^{25-27}$ Elevated serum creatinine was found in more than $50 \%$ of the patients in our study on admission. It was found to be a significant indicator of mortality on its own, but, when adjusted for age it was insignificant. This points towards the importance of increased age as a determinant of mortality in patients with COVID-19.

\section{Conclusion}

In conclusion, COVID-19 was associated with increased mortality in patients who required intubation, which reflects the severity of pneumonia, and in the elderly, which may be explained by changes in the immune system from aging. Elevated BMI, though not statistically significant, was present in the majority of our study population, which may have contributed to the group's high mortality; this finding may reflect a baseline inflammatory state propitiated by obesity itself and worsened by a devastating infection such as that from SARS-CoV-2. ${ }^{28}$

\section{Acknowledgement}

This manuscript is dedicated to the staff members of Metropolitan Hospital with special recognition to the hospitalist group led by Dr. Noella Boma, who showed extraordinary courage and compassion to attend the community of East Harlem in New Yok City.

\section{Conflicts of interest}

Author declares there are no conflicts of interest.

\section{Funding}

None.

\section{References}

1. https://coronavirus.jhu.edu/map.html

2. Li X, Xu S, Yu M, et al. Risk factors for severity and mortality in adult COVID-19 inpatients in Wuhan. J Allergy Clin Immunol. 2020;146(1):110-118.

3. Zhou F, Yu T, Du R, et al. Clinical course and risk factors for mortality of adult inpatients with COVID-19 in Wuhan, China: a retrospective cohort study. Lancet. 2020;395(10229):1054-1062.

4. Shady A, Singh A P, Gbaje E, et al. Characterization of Patients with COVID-19 Admitted to a Community Hospital of East Harlem in New York City. Cureus. 2020;12(8):e9836.

5. Divo MJ, Martinez CH, Mannino DM. Ageing and the epidemiology of multimorbidity. Eur Respir J. 2014;44(4):1055-1068.

6. Meyer KC. Lung infections and aging. Ageing Res Rev. 2004;3(1):55-67.

7. Dewan SK, Zheng SB, Xia SJ, et al. Senescent remodeling of the immune system and its contribution to the predisposition of the elderly to infections. Chin Med J (Engl). 2012;125(18):3325-3331.

8. Lim WS, van der Eerden MM, Laing R, et al. Defining community acquired pneumonia severity on presentation to hospital: an international derivation and validation study. Thorax. 2003;58(5):377-382.

9. Fine MJ, Auble TE, Yealy DM, et al. A prediction rule to identify lowrisk patients with community-acquired pneumonia. $N$ Engl $J$ Med. 1997;336(4):243-250.

10. Godaert L, Proye E, Demoustier-Tampere D, et al. Clinical characteristics of older patients: The experience of a geriatric short-stay unit dedicated to patients with COVID-19 in France. J Infect. 2020;81(1): e93-e94.

11. Beloosesky Y, Weiss A, Hershkovitz A, et al. Atypical illness presentation in the elderly. Isr Med Assoc J. 2000;2(7):540-543.

12. Costa FF, Rosário WR, Ribeiro Farias AC, et al. Metabolic syndrome and COVID-19: An update on the associated comorbidities and proposed therapies. Diabetes Metab Syndr. 2020;14(5):809-814.

13. Marhl M, Grubelnik V, Magdič M, Markovič R. Diabetes and metabolic syndrome as risk factors for COVID-19. Diabetes Metab Syndr. 2020;14(4):671-677.

14. https://www.cdc.gov/nchs/fastats/hypertension.htm

15. Guan WJ, Ni ZY, Hu Y, et al. Clinical Characteristics of Coronavirus Disease 2019 in China. N Engl J Med. 2020;382(18):1708-1720.

16. Richardson S, Hirsch JS, Narasimhan M, et al. Presenting Characteristics, Comorbidities, and Outcomes Among 5700 Patients Hospitalized With COVID-19 in the New York City Area. JAMA. 2020;323(20):2052-2059.

17. Zhou F, Yu T, Du R, et al. Clinical course and risk factors for mortality of adult inpatients with COVID-19 in Wuhan, China: a retrospective cohort study. Lancet. 2020;395(10229):1054-1062. 
18. Lin CK, Lin CC. Work of breathing and respiratory drive in obesity. Respirology. 2012;17(3):402-411.

19. Salome CM, King GG, Berend N. Physiology of obesity and effects on lung function. J Appl Physiol.1985). 2010;108(1):206-211.

20. King GG, Thamrin C. Obesity and the lungs: Not just a crush. Respirology. 2019;24(6):502-503.

21. Ackermann M, Verleden SE, Kuehnel M, et al. Pulmonary Vascular Endothelialitis, Thrombosis, and Angiogenesis in Covid-19. N Engl J Med. 2020;10.1056/NEJMoa2015432.

22. Hariri L, Hardin CC. Covid-19, Angiogenesis, and ARDS Endotypes. $N$ Engl J Med. 2020;383(2):182-183.

23. Mentzer SJ, Konerding MA. Intussusceptive angiogenesis: expansion and remodeling of microvascular networks. Angiogenesis. 2014;17(3):499 509.
24. Reynolds AS, Lee AG, Renz J, et al. Pulmonary Vascular Dilatation Detected by Automated Transcranial Doppler in COVID-19 Pneumonia. Am J Respir Crit Care Med. 2020;202(7):1037-1039.

25. Zheng Z, Peng F, Xu B, et al. Risk factors of critical \& mortal COVID-19 cases: A systematic literature review and meta-analysis. $J$ Infect. 2020;81(2):e16-e25.

26. Pei G, Zhang Z, Peng J, et al. Renal Involvement and Early Prognosis in Patients with COVID-19 Pneumonia. $J$ Am Soc Nephrol. 2020;31(6):1157-1165.

27. Cheng Y, Luo R, Wang K, et al. Kidney disease is associated with inhospital death of patients with COVID-19. Kidney Int. 2020;97(5):829838.

28. de Heredia FP, Gómez-Martínez S, Marcos A. Obesity, inflammation and the immune system. Proc Nutr Soc. 2012;71(2):332-338. 